and 4 of 7 living sibs showed a balanced translocation from the long arm of a number 13 chromosome to the long arm of a number 3 chromosome. We stress the importance of investigating the families of children with chromosomal defects.

References

Allderdice, P. W., Davis, J. G., Miller, O. J., Klinger, H. P., Warburton, D., Miller, D. A., Allen, F. H., Jr., Abrams, C. A. L., and McGilvray, E. (1969). The 13q-deletion syndrome. American Journal of Human Genetics, 21, 499-512.

De Grouchy, J. (1976). Human chromosomes and their anomalies. Aspects of Genetics in Paediatrics, p. 5. Report of the Third Unigate Paediatric Workshop. Ed. by D. Barltrop. Fellowship of Postgraduate Medicine, London.

Grace, E., Drennan, J., Colver, D., and Gordon, R. R. (1971). The 13q-deletion syndrome. Journal of Medical Genetics, 8, 351-357.

Lewandowski, E. C., Jr., and Yunis, J. J. (1975). New chromosomal syndromes. American Journal of Diseases of Children, 129, 515-529.

McCandless, A., and Walker, S. (1976). $D_{13}$ ring chromosome syndrome. Archives of Disease in Childhood, 51, 449-453.

Paris Conference (1972). Standardization in human cytogenetics. Birth Defects: Original Article Series, 8, No. 7. The National Foundation, March of Dimes.

Stoll, C., and Halb, A. (1974). Trisomie 13 partielle par translocation 46XX, t(3: 13) (p26: q21) maternelle. Pédiatrie, 29, 725-729.

Schwanitz, G., Reither, G., Grosse, G., Hägele, Ch., Grosse, K.-P., and Gutfried, U. (1975). Partial monosomy 13 as a result of a balanced translocation $3 / 13$ pat. Humangenetik, 28, 93-96.

A. Carmichael, D. P. Addy, W. R. ShortlandWebb, A. H. Cameron, and Islay C. S. Davies Departments of Paediatrics and Pathology, Dudley Road Hospital, and Department of Cytogenetics, Children's Hospital, Birmingham.

Correspondence to Dr. D. P. Addy, Department of Paediatrics, Dudley Road Hospital, Dudley Road, Birmingham B18 7QH.

\section{Failure to thrive at the breast: an old problem revisited}

In recent years there has rightly been considerable effort to persuade British mothers to breast feed (Department of Health and Social Security, 1974; Sloper et al., 1975). Although not totally successful, there are now more mothers attempting breast feeding than for some considerable time.

Breast feeding is not without its complications, however. One well-known problem is underfeeding. Typically these infants are restless, cry excessively, and fail to gain weight adequately (James, 1956; Shanks, 1973). However, there is another presentation of underfeeding which, although well recog- nized by earlier paediatricians, may be less appreciated by the present generation of doctors and nurses. This is the breast-fed infant who fails to thrive without complaint. We have already drawn attention to the problem in a report of extremely poor weight gain in such an infant (Davies and Evans, 1977). We here describe a further 4 infants who as well as showing poor weight gain, also show varying degrees of retardation of gain in length and head growth.

\section{Case reports}

Four infants were born at term after uncomplicated pregnancies and deliveries. They were of appropriate size for gestation and had no neonatal problems. Each infant was entirely breast fed. There were no early problems with breast engorgement or sore nipples. The mothers of 3 infants had previously successfully breast fed at least one infant and they were all intelligent women from good social backgrounds.

The infants were between 8 and 12 weeks old. 3 were seen at a hospital 'well baby' clinic, and the fourth was an outpatient referral. All looked emaciated. As well as showing very poor weight gain they also showed growth failure of length and head circumference to a varying extent (Fig.). The mothers

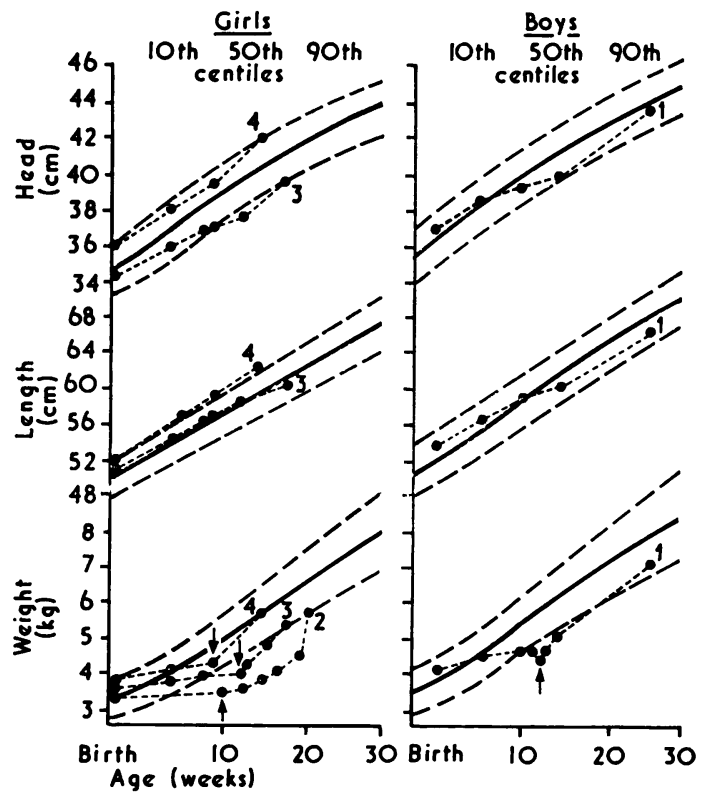

Fig. Growth patterns of the 4 infants. The 10th, 50th, and $90 \mathrm{th}$ centiles are from the data of Gairdner and Pearson (1971). The arrows indicate the start of bottle feeds in Cases 1, 2, and 3, and the start of 3-hourly breast feeds in Case 4. 
reported a tendency for their infants to sleep long periods, especially at night, from the early weeks. They were happy with their infants' progress throughout and were feeding 'on demand', being reassured by the knowledge that 'breast is best' and 'a hungry baby is a crying baby'.

Three mothers were encouraged to increase milk supply by feeding every 3 to 4 hours night and day. This succeeded in one infant (Case 4). The other infants gained weight rapidly only on starting bottle feeds.

\section{Discussion}

The case histories described in this paper are clear examples of infants who uncomplainingly fail to thrive from underfeeding. Furthermore, we believe from discussion with other paediatricians and nurses in other parts of the UK that this problem might be more common than is generally appreciated. Doctors and nurses should be alerted to the 'wasted' but contented breast-fed infant. This will only be achieved if the emphasis in infant welfare clinics is on accurate measurement of naked weight with a clinical estimate of fat folds and careful use of up-todate weight charts.

Why some apparently normal infants should uncomplainingly starve is an intriguing question. Our 4 infants shared a tendency to accept long intervals between feeds which dated since birth. Presumably they had a defect in appetite control in the opposite direction to infants who demand feed in excess of their needs and become obese. Breast-fed infants tend to get a diminishing supply with a diminishing demand and may enter a vicious circle ending in irretrievable failure of lactation. In Case 4 we think that we were able to break this cycle by 'forced feeding'.

\section{Summary}

Four apparently normal breast-fed infants failed to thrive when fed on demand. They all shared a tendency to accept long intervals between feeds from birth. Infant welfare clinics should be alerted to this problem. If infants who attend these clinics are accurately weighed and their progress carefully recorded on weight charts this insidiously developing complaint could be detected earlier and with appropriate advice, a potentially serious condition averted.

We thank Professor O. P. Gray for advice and for permission to describe a patient under his care.

\section{References}

Davies, D. P., and Evans, T. J. (1977). Failure to thrive at the breast. Lancet, 2, 1194.

Department of Health and Social Security (1974). Present Day Practices in Infant Feeding. Report on Health and Social Subjects No. 9. HMSO, London.

Gairdner, D., and Pearson, J. (1971). A growth chart for premature and other infants. Archives of Disease in Childhood, 46, 783-787.

James, U. (1956). Feeding in Infancy and Early Childhood, p. 88. Faber and Faber, London.

Shanks, R. A. (1973). Infant feeding. Textbook of Paediatrics, p. 209. Ed. by J. O. Forfar and G. C. Arneil. Churchill Livingstone, Edinburgh and London.

Sloper, K., McLean, L., and Baum, J. D. (1975). Factors influencing breast feeding. Archives of Disease in Childhood, 50, 165-170.

T. J. Evans and D. P. Davies

Department of Child Health, University Hospital of Wales, Cardiff.

Correspondence to Dr. D. P. Davies, Department of Child Health, Leicester Royal Infirmary, Leicester LE1 5WW.

\section{Retention of urine in the neonate possibly due to anticonvulsant drugs}

Congenital infravesical obstruction of urine is readily suspected when an infant has a distended bladder and palpable kidneys. Temporary retention of urine, however, has not been well documented. Shearer $e t$ al. (1972) reported a case of maternal ingestion of nortriptyline during pregnancy causing acute retention which required urethral catheterization. Robson and Davies (1974) discuss 3 cases of transient retention of urine in the neonate with no obvious aetiology. None of their infants suffered any neurological damage; none were given drugs in the first few days of life. Reported here are 3 recent cases of neonatal acute retention of urine, associated with severe birth asphyxia, neonatal convulsions, and the administration of various anticonvulsant drugs.

\section{Case reports}

Case 1. A boy, weighing $4.04 \mathrm{~kg}$, was born at term by emergency caesarean section due to fetal distress and a prolonged second stage. No drugs had been taken during pregnancy. Apgar score at one minute was 1 and the baby required intubation for 5 minutes. At 13 hours the baby had his first convulsion. Treatment was started with phenobarbitone $(22 \cdot 5$ $\mathrm{mg} / 24 \mathrm{~h})$, and dexamethasone $(2 \mathrm{mg} / 24 \mathrm{~h}$ ) was added the next day for continued seizures. Further prolonged convulsions required $1 \mathrm{mg}$ diazepam repeated four times in the period of 36 hours. 